EDITORIAL

\title{
Pre-hospital resuscitation: breathing life into a stale subject
}

\section{F M Weston}

Heart 2004;90:1107-1109. doi: 10.1136/hrt.2004.034223

\section{Is there anything left to learn about the management of cardiac arrest outside hospital?}

in

$\mathrm{n}$ the second half of the 20th century, cardiologists played an influential role both in the development of techniques used in prehospital resuscitation and in the organisation of systems to deliver such emergency care. ${ }^{12}$ In the UK this included doctor manned mobile coronary care units, the training of ambulance crew in advanced life support skills, and the equipping of all emergency ambulances with defibrillators. More recently, however, most British cardiologists have become disinterested and less involved in the management of this manifestation of heart disease.

\section{CARDIOLOGISTS' APATHY}

There are many reasons for this apparent apathy. It is partly explained by the increasing contribution of other specialists in accident and emergency medicine and the expansion of posts for medical directors within the ambulance service, together with the expanding workload of cardiologists within a hospital environment. Moreover, the hoped-for glut of survivors from prehospital cardiac arrest has not materialised. Some large community programmes have reported disappointing survival rates ${ }^{3}$ and the effect of prehospital resuscitation upon overall community death rates is small. ${ }^{4}$ There is also a perception that there is nothing new to learn about resuscitation. After all, basic life support techniques have changed little over the past 40 years, community training programmes in cardiopulmonary resuscitation are well established, and ambulance paramedics can deliver both defibrillation and, in many cases, drugs, according to advanced life support protocols. The links within the "chain of survival" have been well described $^{5}$ and the predictors of survival are confirmed, and found to be similar in most studies. These predictors of survival appear self evident: the absence of co-morbidity, a witness to the collapse, prompt cardiopulmonary resuscitation (CPR) of good quality by a bystander, a "shockable rhythm" on arrival of the defibrillator, and prompt defibrillation.

Yet it is important that cardiologists do not become completely divorced from the delivery of attempted resuscitation outside hospital. Sudden cardiac death outside hospital remains a frequent first manifestation of heart disease. ${ }^{6}$ The majority of fatalities caused by acute myocardial infarction occur before hospitalisation, ${ }^{7}$ and pre-hospital resuscitation is felt to prevent more deaths than does thrombolytic
Correspondence to: Clinical Effectiveness and Evaluation Unit, Roya College of Physicians of ............... treatment delivered within hospital. ${ }^{8}$ Further, there are encouraging signs that fresh approaches to basic life support ${ }^{9}$ and drug treatments during cardiac arrest ${ }^{10}$ will lead to improved outcomes. Also, there is an important debate to be joined about the provision of public place defibrillation. ${ }^{11}{ }^{12}$

\section{WHEN NOT TO START}

In this issue of Heart, Herlitz and colleagues ${ }^{13}$ present data from the Swedish Cardiac Arrest Registry concerning those patients who could have been identified as having no chance of survival when the ambulance crew arrived. They conclude that in those patients found to be in a non-shockable rhythm (asystole or pulseless electrical activity), where the collapse was unwitnessed at home and bystanders have not attempted resuscitation (17\% of those where resuscitation was attempted), ambulance crews might refrain from starting resuscitation attempts-especially if the delay from receiving the emergency call and arrival at the scene is prolonged..$^{13}$ Moreover, they report that in 8111 cases $(21 \%$ of reports) no CPR was started. It should be noted that most of the ambulance personnel used advanced life support techniques, including endotracheal intubation and drug administration.

Herlitz and colleagues ${ }^{13}$ make reference to other researchers who have attempted to describe the characteristics of patients and their cardiac arrests that predict the hopelessness, and therefore the inappropriateness, of resuscitation attempts. In a further, and smaller, Scottish study of cardiac arrests attended by ambulance personnel with semi-automatic advisory defibrillators but no drug treatments, there were no survivors among the group characterised by the combination of an arrest before ambulance arrival, a "non-shockable" rhythm, no bystander CPR, and with an ambulance response time of more than 15 minutes. ${ }^{14}$ Last year a subcommittee of the Joint Royal Colleges' Ambulance Liaison Committee published a report on the "Recognition of life extinct" by ambulance personnel. It suggests that British paramedics should avoid starting resuscitation when they arrived at the scene more than 15 minutes after the onset of the arrest, when an automated defibrillator failed to recognise a shockable rhythm, where no bystander CPR had taken place before their arrival, and where a monitor showed asystole for 30 seconds. ${ }^{15}$ Interestingly,

Abbreviations: CCAD, Central Cardiac Audit Database; CPR, cardiopulmonary resuscitation; MINAP, Myocardial Infarction National Audit Project; NSF, National Service

Framework 
even when these criteria are met, the report instructs the ambulance crew to instigate resuscitation attempts if urged to do so by an attending general practitioner or by a relative or close friend of the deceased.

While the conclusions of the paper by Herlitz and colleagues $^{13}$ are not surprising, it is but one of many informative articles from this group, whose interest in prehospital cardiac arrest began as a study of local activity and developed into a prospective national survey. Their findings have the added validity inherent in this method of data collection where large numbers of cases are accumulated over time.

\section{NATIONAL REGISTRIES}

The Swedish Registry started in 1990 as a cooperation between a few ambulance services and local cardiologists, later received government funding, and by 1995 included 57 ambulance services covering $85 \%$ of the inhabitants of the country. It is specifically a collaboration between the Swedish ambulance and emergency services and the Swedish Society of Cardiology. A common dataset is used to record information regarding attempted resuscitation, a central computerised registry is established, and the status (alive or dead) of patients one month after the cardiac arrest is obtained from subsequent local inquiry (presumably from the admitting hospital) or from the National Registry of Deaths. Over the duration of the present article (1990-2001), 38750 cases of cardiac arrest were reported.

In the UK, only in Scotland is there a truly national database for prehospital cardiac arrest: the HeartStart Scotland database. By 21 March 2003 this held information on 37182 cases of out-of-hospital cardiac arrest, with a linkage between the management of cardiac arrest by the Scottish Ambulance Service and vital status. ${ }^{16}$

In the rest of the UK, reported series of out-of-hospital cardiac arrests have tended to be of shorter time scale and to reflect a population served by particular hospitals or by individual ambulance services ${ }^{17}{ }^{18}$ or small groups of localities. ${ }^{7}$ The numbers of arrests studied are far smaller than the Swedish and Scottish studies. Valid recording has needed exhaustive case finding, often by individuals on short term research fellowships. ${ }^{19}$ Until the advent of the Utstein recommendations for the reporting of out-of-hospital cardiac arrest, $^{20}$ comparison between ambulance services has been difficult. Furthermore, reporting systems continue to differ between the various ambulance services and there is no direct linkage between ambulance service records of clinical care and hospital systems that record outcomes following hospital admissions. Ambulance services are not co-terminus with special health authorities, and individual hospitals are often served by a variety of ambulance services. Standards for the emergency services have tended to emphasise the rapidity of response, the provision of specific equipment, and the quality of staff training, rather than clinical outcomes. All this has tended to work against the development of a national prehospital cardiac arrest database that expresses clinically meaningful long term outcomes (for example, "survival at one year").

\section{ADVANTAGES OF NATIONAL REGISTRIES}

Hospital based registries have been used successfully to demonstrate temporal changes in management and outcome of myocardial infarction. ${ }^{21}$ Such registries facilitate observational research and provide clinically useful activity data for health care planning. Being locally delivered, they are not reliant upon central government or pharmaceutical industry funding, and are not endangered by changes in political priorities. But their findings may not be generalisable to other hospitals. Larger registries, involving common definitions and methods of data collection across a variety of hospitals, have the added advantage of allowing the description of regional variations in practice and outcome.22 Such schemes have tended to be rather short term and to include only "volunteer" centres, whose practice may not reflect the true variation of clinical care.

All acute hospitals in England and all except one such hospital in Wales contribute data to the Myocardial Infarction National Audit Project (MINAP). This is a prospective continuous audit of heart attack management, whereby a strictly defined dataset of items is transmitted electronically to a central database. Individual hospitals can access their own records at any time, and compare against national averages. A public report, presenting aggregate data for each hospital with respect to performance indicators of good practice, is published annually. Linkage to the UK Office of National Statistics allows vital status (survival) to be recorded and fed back to participating centres. The blanket coverage achieved by MINAP allows rapid detection of changes in practice throughout an entire country, though numbers of cases from individual hospitals make interhospital comparison unreliable. ${ }^{23} 24$

An integral aspect of MINAP is a systematic annual quality control exercise via compulsory validation of 20 case notes from each hospital against previously entered data. Such a quality control mechanism is absent from both the Swedish and Scottish cardiac arrest databases. This is important because independent data validation exercises in similar registries have shown substantial errors in data entry. ${ }^{25}$

One of the driving forces behind MINAP was the National Service Framework (NSF) for coronary heart disease. The NSF also emphasised the importance of prehospital resuscitation. Using a methodology similar to MINAP, it should be possible to produce a national resuscitation database, leading to information on every collapse where resuscitation outside hospital is attempted. Through this, the work of the ambulance services with respect to cardiac care could be embraced within the Central Cardiac Audit Database $(\mathrm{CCAD}),{ }^{26}$ which presently manages a variety of cardiac datasets including MINAP. Simple linkage to the Office of National Statistics would allow the automatic retrieval of long term outcomes of out-of-hospital cardiac arrest. Furthermore, using a common patient identifier the entire "cardiac career" of an individual could be mapped-for example, from successful resuscitation from cardiac arrest outside hospital through coronary bypass grafting to implantation of a defibrillator, or from an initial presentation with acute myocardial infarction through percutaneous intervention to subsequent cardiac arrest in the community.

\section{CONCLUSIONS}

The management of cardiac arrest in the community remains an important facet of cardiac care. Countries that have established national registries are in a strong position to monitor the success of systems of delivering prehospital resuscitation. Using MINAP methodology a national resuscitation dataset should be established with links, via the CCAD, to other datasets, and with central tracking of mortality. Cardiologists should renew an interest in the emergency management of heart disease in their communities.

\section{REFERENCES}

1 Pantridge JF, Geddes JS. A mobile intensive care unit in the management of myocardial infarction. Lancet 1976;ii:271-3.

2 Briggs RS, Brown PM, Crabb ME, et al. The Brighton resuscitation ambulances: a continuing experiment in prehospital care by ambulance staff. BMJ 1976;ii:1161-5.

3 Lombardi G, Gallagher J, Gennis P. Outcome of out-of-hospital cardiac arrest in New York City. The pre-hospital arrest survival evaluation (PHASE) study. JAMA 1994;271:678-83. 
4 Leslie WS, Fitzpatrick B, Morrison CE, et al. Out-of-hospital cardiac arrest due to coronary heart disease: a comparison of survival before and after the introduction of defibrillators in ambulances. Heart 1996;75:195-9.

5 Advanced Cardiac Life Support Committee and Emergency Care Committee of the American Heart Association. Improving survival from sudden cardiac arrest 'the chain of survival concept'. A statement for health professionals. Circulation 1991;83:1832-47.

6 Cobb LA, Fahrenbruch CE, Olsufka M, et al. Changing incidence of out-ofhospital ventricular fibrillation, 1980-2000. JAMA 2002;288:3008-13.

7 United Kingdom Heart Attack Study Collaborative Group. Fatality outside hospital from acute coronary events in three British health districts 1994-5. BMJ 1998;316:1065-70.

8 Julian DG, Norris RM. Myocardial infarction: is evidence-based medicine the best? Lancet 2002;359:1515-16.

9 Wik L, Hansen TB, Fylling F, et al. Delaying defibrillation to give basic cardiopulmonary resuscitation to patients with out-of hospital ventricular fibrillation: a randomised trial. JAMA 2003;289:1389-95.

10 Wenzel V, Krisner A, Arntz R, et al. A comparison of vasopressin and epinephrine for out-of-hospital cardiopulmonary resuscitation. N Engl J Med 2004:350:105-13.

11 Pell JP. The debate on public place defibrillators: charged but shockingly ill informed. Heart 2003;89:1375-6.

12 Priori SG, Bossaert LL, Chamberlain DA, et al. ESC-ERC recommendations for the use of automated external defibrillators (AEDs) in Europe. Eur Heart $J$ 2004; $25: 437-45$

13 Herlitz J, Engdahl J, Svennson L, et al. Can we define patients with no chance of survival after out-of-hospital cardiac arrest? Heart 2004;90:1114-8.

14 Marsden AK, Ng GA, Dalziel K, et al. When is it futile for ambulance personnel to initiate cardiopulmonary resuscitation? BMJ 1995;311:49-51.

15 www.asancep.org.uk/JRCALC/ROLE_Most_FINAL_Marc15, h2003.pdf (accessed 10 April 2004).
16 www. Ishtm.ac.uk/docdat/records.php? $\mathrm{t}=$ records\&id = HEA16, RTSTART laccessed 10 April 2004

17 Weston CFM, Jones SD, Wilson RJ. Outcome of out-of-hospital cardiorespiratory arrest in South Glamorgan. Resuscitation 1997;34:227-33.

18 Soo LH, Gray D, Young T, et al. Resuscitation from out-of-hospital cardiac arrest: is survival dependent on who is available at the scene? Heart 1999;81:47-52.

19 United Kingdom Heart Attack Study Collaborative Group. Effect of time from onset to coming under care on fatality of patients with acute myocardial infarction: effect of resuscitation and thrombolytic treatment. Heart 1998:80:114-20

20 Cummins RO, Chamberlain DA, Abramson NS, et al. Recommended guidelines for uniform reporting of data from out-of-hospital cardiac arrest: the Utstein Style. Circulation 1991;84:960-75.

21 Gray D Hampton JR. Twenty years experience of myocardial infarction: the value of a heart attack register. Br J Clin Pract 1993;47:292-5.

22 Eagle KA, Goodman SG, Avezum A, et al. Practice variation and missed opportunities for reperfusion in ST-segment-elevation myocardial infarction: findings from the global registry of acute coronary events (GRACE). Lancet 2002:359:373-7.

23 Birkhead JS, Walker L, Pearson $M$, et al. Improving care for patients with acute coronary syndromes: initial results from the national audit of myocardia infarction project (MINAP). Heart 2004;90:1004-9.

24 Norris RM, Lowe D, Birkhead JS. Can successful treatment of cardiac arrest be a performance indicator for hospitals? Resuscitation 2004;60:263-9.

25 Gibbs JL, Monro JL, Cunnigham D, et al. Survival after surgery or therapeutic catheterisation for congenital heart disease in children in the United Kingdom: analysis of the central cardiac audit database for 2000-1. BMJ 2004; 328:611-5.

26 Rickards $A$, Cunningham AD. From quantity to quality: the central cardiac audit database. Heart 1999;82(suppl 2):18-22.

\section{IMAGES IN CARDIOLOGY}

\section{Transthoracic echocardiography of a congenital left circumflex artery to coronary sinus fistula}

A 37 year old man presented with a continuous murmur throughout both phases of systole and diastole. A transthoracic echocardiogram showed an enlarged left main stem $(1.15 \mathrm{~cm})$ coronary artery (panel A) with colour flow predominantly upwards into the left circumflex artery (panel B). The parasternal short axis view at the papillary muscle level showed coils of the fistula posteriorly (panel C) with flow demonstrated on the colour flow Doppler (panel D). The four chamber apical view demonstrated in panel E shows an enlarged coronary sinus (CS). On coronary angiogram there was a large left circumflex artery draining via a tortuous fistula into the coronary sinus.

Congenital coronary artery fistula is a rare anomaly for which the gold standard for diagnosis is coronary angiography. Transthoracic echocardiography was, however, able to assess the coronary anatomy accurately in this case.

D S Gill

Q-W Yong

K-S Ng

dal3@hotmail.com
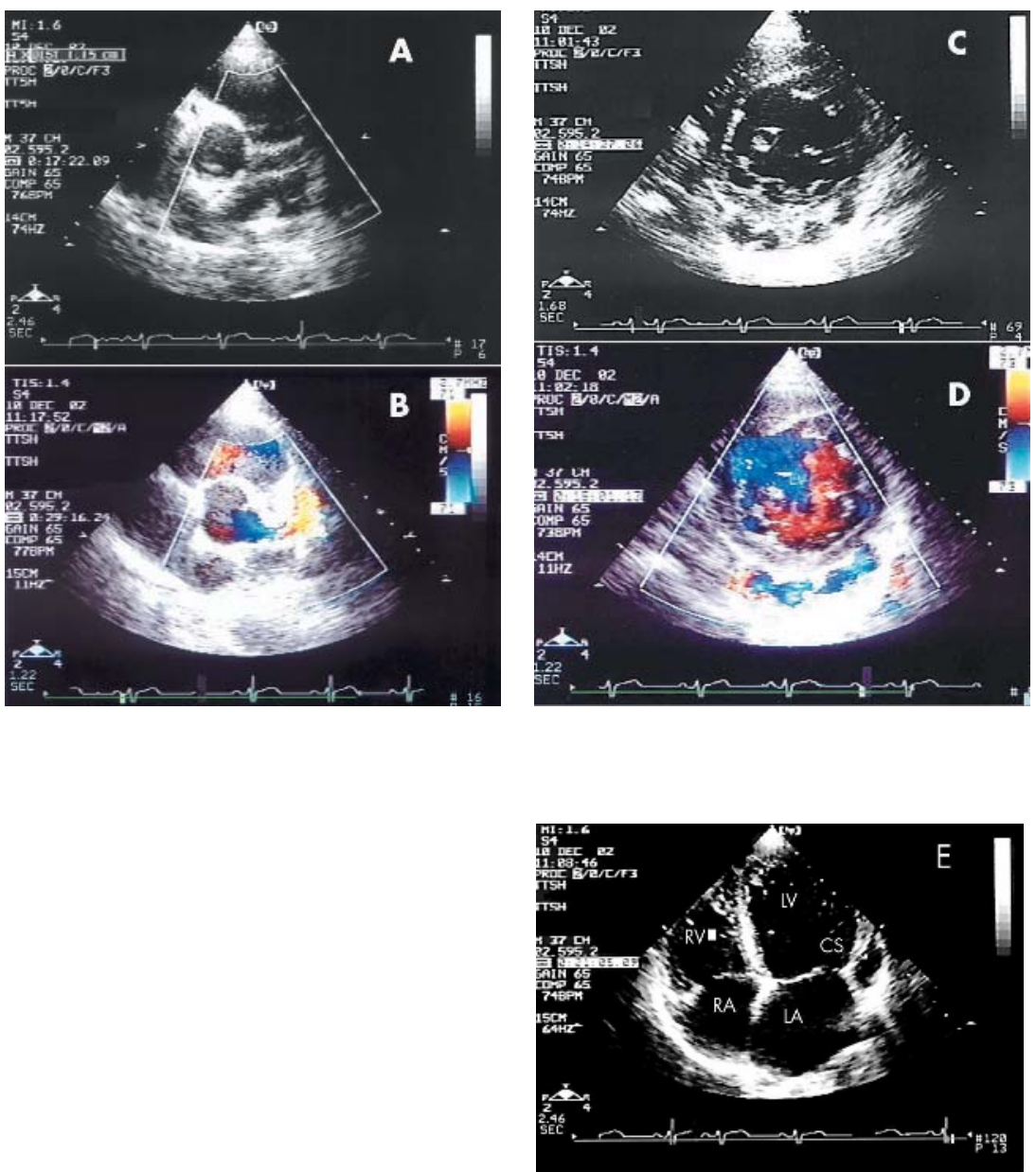